
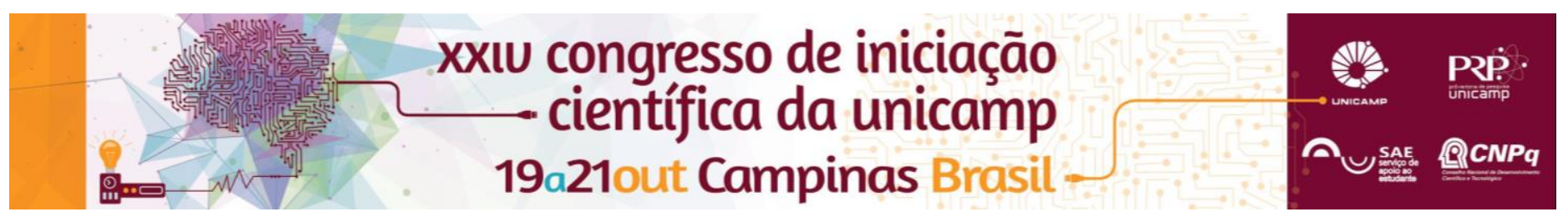

\title{
Introdução à otimização linear e aplicações
}

\author{
Lucas Galdino de Camargo*, Dra. Kelly Cristina Poldi.
}

\section{Resumo}

Problemas de Otimização Linear ou Programação Linear (PL) são problemas de otimização nos quais a função objetivo e as restrições são todas lineares. Muitos problemas práticos em pesquisa operacional podem ser expressos como problemas de otimização linear. Há vários métodos de solução na literatura para resolução de problemas de otimização linear, dentre eles, destacam-se o Método Simplex e Método de Pontos Interiores. Neste trabalho, discute-se o Método Simplex, sua fundamentação teórica e algoritmo, e a implementação utilizando o pacote de otimização AMPL1.

\section{Palavras-chave:}

Otimização linear, programação linear, modelagem matemática.

\section{Introdução}

Afim de explorar os resultados relevantes ao método simplex, resolveremos o problema de mix de produção?: Um fabricante de geladeiras precisa decidir quais modelos deve produzir em uma nova fábrica recentemente instalada. O departamento de marketing e vendas realizou uma pesquisa de mercado que indicou que, no máximo, 1.500 unidades do modelo de luxo e 6.000 unidades do modelo básico podem ser vendidas no próximo mês. A empresa já contratou um certo número de empregados e, com isso, dispõe de uma força de trabalho de 25.000 homens-hora por mês. Cada modelo de luxo requer dez homens-hora e cada modelo básico requer oito homens-hora para ser montado. Além disso, uma mesma linha de montagem é compartilhada pelos dois modelos e considere que a capacidade de produção desta linha seja de 4.500 geladeiras por mês. O lucro unitário do modelo de luxo é de $\$ 100,00$, e do modelo básico é de $\$ 50,00$. Deseja-se determinar quanto produzir de cada modelo de modo a maximizar o lucro da empresa.

\section{Resultados e Discussão}

Para iniciar a resolução, escrevemos o modelo de otimização para o problema descrito acima, que fica:

Maximizar $f\left(x_{\text {luxo }}, x_{\text {básico }}\right)=100 x_{\text {luxo }}+50 x_{\text {básico }}$

Sujeito à:

$$
\begin{gathered}
10 x_{\text {luxo }}+8 x_{\text {básico }} \leq 25.000 \\
x_{\text {luxo }}+x_{\text {básico }} \leq 4.500 \\
0 \leq x_{\text {luxo }} \leq 1.500 \text { e } 0 \leq x_{\text {básico }} \leq 6.000
\end{gathered}
$$

Onde $\boldsymbol{x}_{\text {luxo }}$ e $\boldsymbol{x}_{\text {básico são as quantidades a serem }}$ produzidas dos modelos luxo e básico, respectivamente. $\mathrm{Na}$ figura 1, resolvemos o problema graficamente.

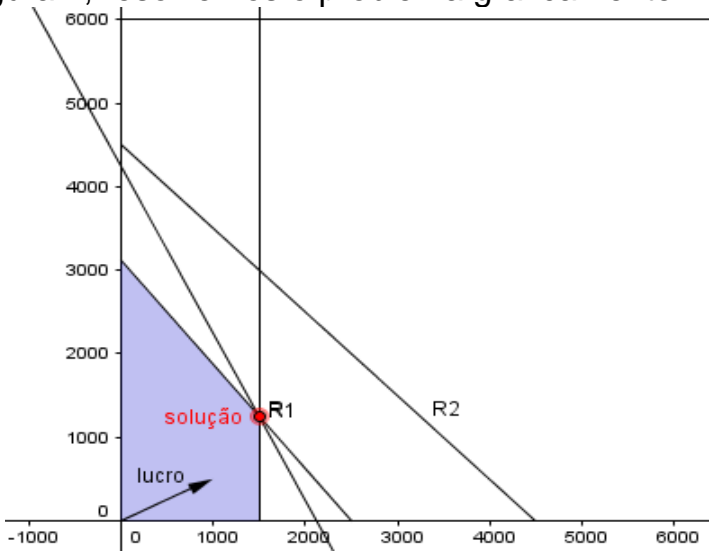

Figura 1. Resolução gráfica (em azul: região factível).
O vetor lucro aponta para a direção de maior crescimento da função objetivo e procuramos, portanto, pelo vértice ótimo nesta direção, encontrando o ponto $\left(\boldsymbol{x}_{\mathbf{l u x o}}=1.500\right.$, $\boldsymbol{x}_{\text {básico }}=1.250$ ). Para o vértice ótimo, a função assume o valor $\$ 212.500,00$. Os mesmos resultados foram encontrados quando resolvemos o problema utilizando o pacote de otimização AMPL - vide figura 2 - porém, para resolver o problema pelo AMPL, consideramos o problema de minimização: $\min -f(x)$, que é equivalente ao problema de maximização.

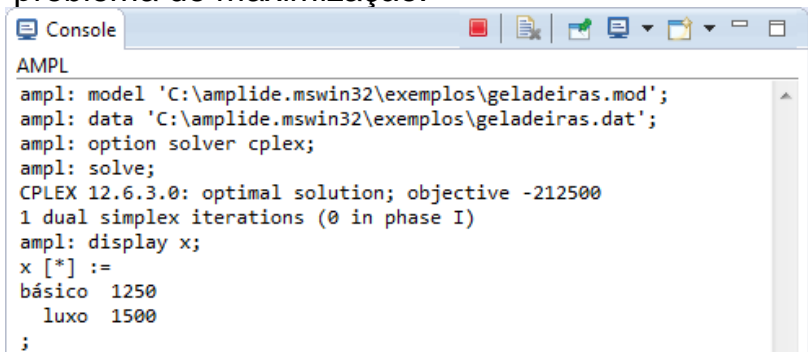

Figura 2. Resolução do problema por meio do AMPL.

\section{Conclusões}

Pudemos sintetizar com um problema bem simples os principais resultados envolvidos na teoria simplex, explorando a modelagem matemática e os aspectos teóricos e computacionais deste método para os problemas de otimização linear.

\section{Agradecimentos}

Agradeço primeiramente à Prof. Dra. Kelly Cristina Poldi, pela oportunidade e por todo o apoio, e ao CNPq, que financiou e tornou o presente trabalho possível.

\footnotetext{
REFERÊNCIAS

1 Fourer, R.; Gay, D. M.; Kernighan, B. W. (2003). AMPL: a modeling language for mathematical programming. $2^{\mathrm{a}} \mathrm{ed}$. Thomson.

${ }^{2}$ Arenales, M. N.; Armentano, V.; Morabito, R.; Yanasse, H. (2006). Pesquisa Operacional.Campus. $1^{\mathrm{a}}$ ed. Rio de Janeiro.

${ }^{3}$ Bazaraa, M. S.; Jarvis, J. J.; Sherali, H. D. (2010). Linear programming and network flows. John Wiley \& Sons. $4^{\text {a }}$ ed. New York.

${ }^{4}$ Goldbarg, M. C.; Luna, H. P. L. (2005). Otimização combinatória e programação linear - modelos e algoritmos. Campus, $2^{\mathrm{a}}$ ed. Rio de Janeiro.

IBM-OPL - Optimization Programming Language. http://www03.ibm.com/software/products/en/ibmilogcpleoptistud/

${ }^{6}$ Griva, I.; Nash, S. G.; Sofer, A. (2009). Linear and nonlinear optimization SIAM - The Society for Industrial and Applied Mathematics. $2^{\mathrm{a}}$ ed. Philadelphia.

${ }^{7}$ Gurobi Optimization. http://www.gurobi.com/index
} 